\title{
Wahyu Utami | Strategic Family Therapy \\ STRATEGIC FAMILY THERAPY UNTUK MEMPERBAIKI KOMUNIKASI DALAM KELUARGA DI NGANJUK
}

\author{
Wahyu Utami \\ ayoe_utami@ymail.com \\ Institut Agama Islam Tribakti Kediri
}

\begin{abstract}
Abstrak
Subjek dalam studi kasus ini adalah anggota keluarga terdiri dari ibu (52 tahun), Anak laki-laki (35 tahun), Anak perempuan (30 tahun), menantu (32 tahun) dan cucu (4 tahun). Metode assesment yang digunakan adalah wawancara, observasi dan skala pengukuran. Hasil asesmen menunjukkan bahwa keluarga mengalami kegagalan dalam pola komunikasi, interaksi dalamkeluarga kaku dan saling menutup diri. Intervensi yang digunakan adalah strategic family therapy dalam enam sesi, yang bertujuan untuk mengubah komunikasi antar anggota keluarga. Hasil intervensi menunjukkan bahwa masing-masing anggota keluarga menjadi lebih terbuka dan tidak ada lagi salah paham antar anggota serta ada kerjasama dalam melaksanakan tanggungjawab terkait pekerjaan rumah tangga.
\end{abstract}

Kata kunci: Strategic family therapy, komunikasi, keluarga

\begin{abstract}
Subjects in this case study were family members consisting of mother (52 years), boy (35 years), daughter (30 years), son (32 years) and grandchild (4 years). Assessment method used is interview, observation and measurement scale. Assessment results indicate that families experience failure in communication patterns, interactions in families rigid and close each other. The intervention used was strategic family therapy in six sessions, aimed at changing communication among family members. The results of the intervention show that each family member becomes more open and there is no misunderstanding among members and there is cooperation in carrying out the responsibilities related to domestic work.
\end{abstract}

Keywords: Strategic family therapy, communication, family 


\section{Wahyu Utami | Strategic Family Therapy}

\section{Latar Belakang}

Sebuah keluarga adalah sebuah sistem sosial yang alami, dimana seseorang menyusun aturan, peran, struktur kekuasaan, bentuk komunikasi, cara mendiskusikan pemecahan masalah sehingga dapat melaksanakan berbagai kegiatan dengan lebih efektif. Dalam penjelasan yang lain dikatakan bahwa keluarga adalah suatu unit yang berfungsi sesuai atau tidak sesuai menurut tingkat persepsi peran dan interaksi di antara kinerja peran dari macam-macam anggota. Salah satu perspektif fungsional dalam system keluarga adalah bagaimana cara keluarga melindungi, merawat dan mendidik anak. Bagaimana membuat lingkungan fisik, social dan ekonomi untuk mendukung perkembangan individu, bagaimana menciptakan ikatan yang kuat dan terpelihara, bagaimana orangtua mendidik anak supaya sukses dikehidupan dunia (Almasitoh, 2012).

Keluarga merupakan sistem sosialisasi bagi anak, dimana ia mengalami pola disiplin dan tingkah laku AEektif. Walaupun seorang anak telah mencapai masa remaja dimana keluarga tidak lagi merupakan pengaruh tunggal bagi perkembangan mereka, keluarga tetap merupakan dukungan yang sangat diperlukan bagi perkembangan kepribadian remaja tersebut. Dengan demikian peran orangtua sangat dibutuhkan, terutama karena bertanggung jawab menciptakan sistem sosialisasi yang baik dan sehat bagi perkembangan moral remaja. Remaja sedang tumbuh dan berkembang, karena itu mereka memerlukan kehadiran orang dewasa yang mampu memahami dan memperlakukannya secara bijaksana (Santrock, 2002).

Menurut Damon (dalam Zainuddin 2004) banyak faktor yang berhubungan dengan perkembangan pemahaman moral remaja antara lain faktor keluarga, teman sebaya, sekolah, media massa, komunitas, perkembangan kognitif, kepribadian dan lainlain. Diantara faktor-faktor lingkungan, faktor keluarga adalah faktor yang sangat berpengaruh terhadap pemahaman moral remaja. Pendapat ini diperkuat oleh Yusuf (2006) yang mengatakan bahwa ada beberapa faktor yang berhubungan 


\section{Wahyu Utami | Strategic Family Therapy}

dengan pemahaman moral remaja antara lain konsistensi dalam mendidik, penghayatan dan pengamalan agama yang dianut, sikap konsistensi orangtua dalam menerapkan norma, dan sikap orangtua dalam keluarga. Orangtua merupakan faktor primer bagi perkembangan anak karena yang pertama kali memperkenalkan anak pada hukum dan sistem sosial adalah orangtua, maka orangtua merupakan faktor yang sangat penting dalam perkembangan pemahaman moral anak melalui interaksi dalam keluarga (Mounts \& Steinberg, dalam Papalia, 2001).

Pola interaksi dalam keluarga menurut Jackson (2005) ada empat kategori, yaitu; Relasi seimbang dan memuaskan, Tidak seimbang dan memuaskan, Seimbang dan tidak memuaskan. Dengan melakukan komunikasi interpersonal dengan baik akan menghasilkan umpan balik yang baik pula. Komunikasi interpersonal diperlukan untuk mengatur tata krama pergaulan antar manusia, sebab dengan melakukan komunikasi interpersonal dengan baik akan memberikan pengaruh langsung pada struktur seseorang dalam kehidupannya (Cangara, 2006). Komunikasi interpersonal dalam keluarga sangat penting karena dengan adanya komunikasi interpersonal antar sesama anggota keluarga maka akan tercipta hubungan yang harmonis dan dapat diketahui apa yang diinginkan dan yang tidak diinginkan oleh salah satu anggota keluarga. Yang dimaksud dengan komunikasi interpersonal dalam keluarga yaitu hubungan timbal balik antara anggota keluarga untuk berbagi berbagai hal dan makna dalam keluarga. Tujuan dari komunikasi interpersonal dalam keluarga yaitu untuk mengetahui dunia luar, untuk mengubah sikap dan prilaku. Oleh karena itu dengan melakukan komunikasi interpersonal yang baik diharapkan perkembangan pemahaman moral akan berjalan baik pada seorang remaja. (Widjaya, 2000).

Tujuan komunikasi dalam interaksi keluarga ditinjau dari kepentingan orangtua adalah untuk memberikan informasi, nasihat, mendidik dan menyenangkan anak-anak. Anak berkomunikasi dengan orangtua adalah untuk mendapatkan saran, nasihat, masukan dalam memberikan respon dari 
Wahyu Utami | Strategic Family Therapy

pertanyaan orangtua. Komunikasi antar anggota keluarga dilakukan utuk terjadinya keharmonisan dalam keluarga pengalaman antar satu dengan yang lain. Dan dari setiap komunikasi yang dilakukan dalam keluarga dapat membuat perubahan perilaku anggota keluarga juga, bearti sebagai keterbukaan dari setiap anggota keluarga apabila dari salah satu anggota keluarga mengalami masalah yang menyenangkan atau yang tidak menyenangkan, dengan adanya sebuah komunikasi permasalahn yang sedang terjadi di dalam sebuah keluarga itu dapat dibicarakan secara baik-baik untuk mendapatkan solusi yang baik juga (Goldenberg, 2008).

Terapi keluarga adalah cara baru untuk mengetahui permasalahan seseorang, memahami perilaku, perkembangan simtom dan cara pemecahannya. Terapi keluarga dapat dilakukan sesama anggota keluarga dan tidak memerlukan orang lain, terapis keluarga mengusahakan supaya keadaan dapat menyesuaikan, terutama pada saat antara yang satu dengan yang lain berbeda (Almasitoh, 2012). Oleh karena itu, dalam studi kasus ini intervensi yang dapat digunakan untuk meningkatkan pola komunikasi dalam keluarga adalah strategic family therapy. Strategic family therapy dirumuskan sebagai modelyang menggabungkan teknik terapi keluarga struktural dan strategis untuk mengatasisistemik/ relasional (terutama keluarga) dalam interaksi yang berkaitan dengan masalah perilaku remaja yang salah (Szapocznik et al.,2012).

Strategic family therapy berdasarkan konsep Cybernatics yaitu studi yang mempelari bagaimana sistem pemrosesan informasi dikarenakannya ada umpan balik (feedback). Studi ini berasumsi bahwa jika terjadi perilaku psikotik pada salah satu anggota keluarga akan masuk akal ketika keluarga memiliki komunikasi yang patologis pula. Menurut Jay Haley \& Cloe Madanes (2016) keluarga bermasalah akibat dinamika dan struktur keluarga yang disfungsional. Perilaku yang bermasalah merupakan usaha individu untuk mencapai kekuasaaan dan rasa aman (Olson \& Blair, 2007). Strategic family therapy memberikan 


\section{Wahyu Utami | Strategic Family Therapy}

keluarga dengan cara mengurangi factor risiko individu dan keluarga melalui intervensi terfokus yang meningkatkan hubungan keluarga bermasalah dan strategi keterampilan untuk membangun dan memperkuat hubungan keluarga. Salah satu target intervensi adalah hubungan keluarga yangbermasalah.

Terapis akan berperan aktif dalam merencanakan strategi dan mengarahkan jalannya terapi, terlibat langsung dalam mencapai tujuannya untuk mengurangi dan menghilangkan permasalahan-permasalahan yang ada dalam keluarga atau perilaku yang nampak (Goldenberg, 2008). Prosedur Strategic family therapy adalah Social stage yaitu menghadirkan seluruh anggota keluarga dimana setiap keluarga diminta untuk memberikan pendapat yang dihadapi. Terapis menciptakan suasana yang nyaman dimana tidak ada aksi balas dendam dan mengintimidasi. The problem stage yaitu menjelasakan kepada keluarga alasan kenapa mereka harus hadir, memberikan kesempatan kepada masing-masing keluarga untuk berbicara dimulai pada anggota keluarga yang netral yaitu suami. The interaction stage yaitu meminta komentar dari setiap anggota keluarga yang hadir kemudian meminta keluarga untuk membicarakan masalah bersama-sama, dilanjutkan defining desired changes yaitu terapis menyampaikan permasalahannya apa, setelah semua anggota keluarga mengetahui permasalahan yang terjadi. Kemudian terapis menanyakan perubahan seperti apa yang diharapkan, ending the interview yaitu setelah dicapai kesepakatan bersama mengenai definisi masalah kemudian melanjutkan pada sesi pertemuan selanjutnya peemberian tugas, directive directive yaitu menciptakan perilaku berbeda yang selama ini tidak pernah dilakukan sehingga memperoleh pengalaman subjektif yang berbeda, dilanjutkan reframing yaitu bahwa apa yang dilakukan anggota keluarga dengan interpretasi negatif dan di refrom dengan interpretasi positif, sesi terakhir terakhir evaluasi.

Tujuan dari strategic family therapy adalah meningkatkan dan menciptakan pola komunikasi yang baik dalam keluarga 
sehingga keluarga dapat bekerja samamendorong untuk menciptakan keluarga agar berfungsi lebih baik (Santisteban etal., 2003). Karena perubahan yang dibawa dalam pola interaksi keluarga, perubahan-perubahan dalam fungsi keluarga lebih mungkin untuk bertahan setelah pengobatan berakhir, karena beberapa anggota keluarga telah mengubah caramereka berperilakusatu sama lain (Szapocznik et al.,2012).

\section{Metode Penelitian}

\section{Jenis Penelitian}

Metode penelitian ini menggunakan penelitian kualitatif dengan desain one shot case study. Pada metode ini, subjek diberikan intervensi untuk kemudian damati hasilnya (Latipun, 2015).

\section{Subjek Penelitian}

Subjek yang diambil dalam penelitian ini terdiri dari dua kepala keluarga yang meliputi: keluarga 1: Suami, istri, anak lk,. anak pr 1, anak pr 2. Keluarga 2 : (Anak laki-laki), Menantu keluarga 1dan anak perempuan. Teknik pengambil sampel menggunakan porpusive sampling. Adapun kriteria sebagai berikut :

1. Keluarga yang memiliki anggota keluarga inti dengan rentang usia 35-55 tahun

2. Keluarga yang memiliki masalah komunikasi

3. Dalam satu rumah terdiri dari dua kepala keluarga

4. Tinggal di desa ngronggot kabupaten nganjuk

\section{Instrumen}

Wawancara dilakukan dengan anggota keluarga (autoanamnesa), tujuan dari wawancara ini untuk mengumpulkan data-data terkait dengan permasalahan yang terjadi dalam keluarga. Observasi dilakukan pada saat wawancara untuk melihat perilaku keluarga dalam beberapa situasi dan Skala untuk mengukur perilaku yang di buat sendiri oleh peneliti. 


\section{Wahyu Utami | Strategic Family Therapy}

\section{Intervensi dan Hasil Intervensi}

Intervensi dirancangkan sebanyak Tiga sesi dan masingmasing sesi dilakukan selama 60-90 menit. Selama lima sesi dilakukan secara bertahap, dimana sesi satu terdiri dari socialstage, terapis memperkenalkan diri dan perannya sebagai seorang terapis. Setelah dilakukan asesmen terpisah masingmasing subjek, terapis mengumpulkan semua angota keluarga untuk hadir. Terapis membangun raport pada anggota keluarga agar merasa nyaman mengikuti terapi. Sesi dua problem stage, terapis menjelaskan tujuan dari terapi kleuarga yang akan dilaksanakan bersama, selanjutnya terapis meminta dari masingmasing subjek untuk menyampaikan pendapat mengenai permasalahan yang dihadapi. Masing-masing anggota menyampaiakan pendapatnya mengenai permasalahan yang terjadi. Masing-masing anggota keluarga merasakan adanya perubahan anggota keluarga, perubahan yang paling menonjol ditunjukkan oleh SH. Dimana keadaan rumah menjadi sunyi dan sibuk dengan aktifitas masing-masing.

Sesi tiga terdiri dari interaction stage, terapis memberikan kesempatan pada anggota keluarga untuk membicarakan permasalahan yang terjadi dalam keluarga.Saat diskusi berlangsung EM lebih mendominasi pembicaraan, EM meminta SH untuk mengeluarkan semua keluhan-keluhan yang selama ini dipendam.Akan tetapi, ibu SH hanya diam tidak mengehendaki untuk berbicara. Kemudian EM memulai untuk menyampaiakan apa yang dikeluhkan ibu SH selama ini, bahwa ibu SH tidak sependapat dengan keputusan AE untuk memasak secara terpisah karena tidak enak dengan persepsi negatif adri tetangga, EM juga mengatakan bahwa ibu SH mengeluh capek karena harus mengurus rumah seperti mencuci, memasak ditambah dengan kondisi fisik ibu SH yang menurun, keluhan tersebut juga sama seperti yang disampaiakan oleh EF.

DT mengatakan bahwa tidak bermaksud untuk memisahkan diri dari ibu SH, akan tetapi pilihan untuk memasak secara terpisah adalah keputusan dari ibu SH sendiri bukan 


\section{Wahyu Utami | Strategic Family Therapy}

keputusan dari pihak DT maupun AE. Dari awal DT sudah menyampaiakn kepada ibu SH untuk memasak jadi satu, selain untuk meringankan beban ibu SH juga untuk menjalin keharmonisan dalam keluarga, di sisi lain DT juga tidak enak jadi bahan omongan tetangga ketika orang-orang mengetahui bahwa tinggal satu atap akan tetapi melakukan aktifitas memasak secara terpisah, SH sudah memberikan penjelasan tersebut akan tetapi ibu SH tetap memilih untuk memasak secara terpisah.

Ibu SH mengatakan hanya ingin AE menyapanya ketika berada di rumah, ibu SH merasa kesepian karena kedua anak perempuannya tinggal dengan suami, suami beserta anak laki-laki bekerja dari jam 08.00 sd jam 16.00. Sehingga ibu SH merasa kesepian ditambah lagi $\mathrm{AE}$ tidak pernah di lantai satu untuk menemaninya ngobrol walaupun hanya menyapa juga tidak pernah. Hal tersebut membuat AE tidak dekat dengan ibu SH dan justru menangis ketika diajak ke latai satu dan meminta kembali di lantai dua.Ibu SH juga mengeluhkan, seharusnya AE membantu gantian untuk isi ulang Gas, karena ibu SH tidak bekerja dan pengeluaran semakin tambah dengan hadirnya keluarga DT, sehingga ibu SH menginginkan mereka bergantian untuk belanja bahan dapaur. Ibu SH juga mengeluhan capek mengerjakan tugas rumah, Ibu SH menginginkan sesekali AE mencucikan baju SH dan membersihkan rumah

Menantu AE mengungkapkan, bahwa sikap AE yang seperti disampaikan anggota keluarga adalah bukan bermaksud negatif terhadapa ibu SH dan keluarga. Sebelum menikah, AE cenderung pendiam, apalagi dengan profesi $\mathrm{AE}$ sebagai pembantu rumah tangga mulai dari jam 08.00 sd jam 15.00 belum lagi mengurus SB beserta suami DT. Kegiatan tersebut sudah menguras tenaga $\mathrm{AE}, \mathrm{AE}$ meminta maaf karena tidak bisa maksimal dalam mengerjakan pekerjaan rumah, AE juga meminta maaf sekaligus meminta pengertian dari ibu SH mengenai belanja kebutuhan dapur, AE bisa membantu akan tetapi tidak bisa maksimal karena kondisi ekonomi AE beserta suami juga sedang tidak stabil. 


\section{Wahyu Utami | Strategic Family Therapy}

Bapak PH mengungkapkan bahwa ibu SH sering mengeluhkan di rumah ini ada menantu beserta cucu akan tetapi ibu SH masih merasa kesepian. AE beserta cucu jarang komunikasi bersama ibu $\mathrm{SH}, \mathrm{AE}$ turun di lantai satu hanya pada saat akan mandi, mencuci dan memasak selanjutnya kembali lagi ke lantai satu. PH juga tidak nyaman dengan situasi seperti ini, ditambah lagi ibu SH akhir-akhir mengalami penurunan dari segi fisik, hal tersebut membuat bapak PH menjadi lebih khawatir.

Kemudian dilanjutkan dengan defining desired changes, terapis menjelasakan kepada masing-masing subjek mengenai permasalahan dan perilaku yang menyebabkan masalah dalam keluarga. Menantu AE sibuk bekerja dari pagi hingga sore, sepulang dari tempat kerja dilanjutkan mengurus anak dan suami menyiapkan makan dll. Sehingga tidak ada kesempatan untuk komunikasi dengan ibu SH, ditambah lagi menantu AE merasa tidak nyaman setelah kejadian ibu SH memutuskan untuk memasak secara terpisah. Hal tersebut membuat AE semakin tidak enak untuk berkomunikasi dengan ibu $\mathrm{SH}$, tanpa AE sadari bahwa sikapnya justru membuat ibu SH merasa kesepian dan tidak dianggap oleh menantu AE.

\section{Tugas perubahan perilaku yang diharapkan masing-masing anggota keluarga}

(a) Harapan SH (ibu) terhadap AE (Menantu) : Mengharapkan supaya AE bersedia untuk komunikasi dengan $\mathrm{SH}$ dan mengajak SB untuk bermain di lantai satu bersama SH serta ikut kolaborasi dalam hal belanja kebutuhan dapur. (b) Harapan Ipar terhadap AE yaitu supaya kembali memasak bersama-sama ibu SH seperti yang sudah pernah dilakukan. (c) Harapan AE (Menantu) terhadap SH (ibu) agar ibu bisa memahami kesibukan sehari-hari menantu, memahami kondisi ekonomi AE, bersedia untuk memulai menyapa begitu pula sebaliknya dan saling mengingatkan pada saat ada masalah. (d) Harapan AE (Menantu) terhadap kedua adik ipar yaitu untuk tidak berprasangka buruk terhadapnya dan meminta kepada kedua iparnya untuk 


\section{Wahyu Utami | Strategic Family Therapy}

menambah waktu untuk menjenguk ibu SH. (e) Harapan PH (ayah) kepada seluruh anggota keluarga yaitu keluarga menjadi lebih baik tanpa adanya salah paham satu dengan yang lain. Ending interview, perubahan perilaku yang diharapkan itu menjadi tugas masing-masing subjek untuk mencapai perubahan dalam keluarga tersebut. Setelah sepakat mengenai perubahan perilaku, terapis meminta masing-masing subjek selama empat hari dan menggunakan dan melaporkan dengan menggunakan self report. Dilanjutkan dengan reframing yaitu bahwa apa yang dilakukan menantu AE tidak ada maksud negatif, memilih diam karena menghargai keputusan ibu SH dan menghindari adanya masalah.

Sesi tiga pada tanggal terdiri dari tahap Tahap evaluasi. Terapis meminta masing-masing subjek untuk mengumpulkan self report yang telah diberikan pada sesi sebelumnya dan melakukan evaluasi terhadap tugas rumah yang telah disepakati. Berdasarkan self report dan wawancara dilakukan dapat disimpulkan bahwa ibu masih diam dan tidak mau memulai komunikasi terhadap $\mathrm{AE}$, namun pada saat menantu $\mathrm{AE}$ memulai untuk menyapa, ibu SH membalas menyapa. AE juga mengajak cucu SB untuk membiarkan bermain di lantai satu lebih lama bersama ibu SH. Menantu AE ikut berbelanja kebutuhan dapur dan ibu SH bisa memahami keadaaan ekonomi maupun kesibukan AE. Kedua ipar AE bisa memahami dan menerima alasan kenapa AE memasak sendiri dan jarang ke lantai satu untuk menemani ibu SH. Kedua ipar AE sepakat dan bersedia untuk lebih sering menjenguk ibu SH secara bergantian.Dalam hal ini kedua ipar AE tidak lagi salah paham dan berfikir negatif tentang menantu.Begitu juga interaksi dari masing-masing anggota sudah mulai lebih baik dari sebelum intervensi, semua tugas rumah yang diberikan, ada satu tugas yang belum dilakukan yaitu ibu $\mathrm{SH}$ belum bisa menyapa terlebih dahulu kepada menantu $\mathrm{AE}$, kemudian terapis memberikan lagi tugas rumah selama 2 hari tanpa perubahan perilaku yang telah disepakati. 


\section{Wahyu Utami | Strategic Family Therapy}

Sesi empat pada tangga terdiri dari tahap evaluasi. Terapis melakukan evaluasi dari self report yang diberikan kepada masing-masing subjek mengenai perubahan perilaku yang telah disepakati. Dari sesi ini AE 3 hari tidak menjenguk ibu SH karena kelelahan dengan pekerjaan dan jika AE mengajak putrinya untuk bermain di lantai satu akan menambah tenaga yang dikelurkan sehingga AE memutuskan untuk beristirahat di kamar. Akan tetapi AE menjelaskan kepada ibu SH sehingga ibu SH merasa senang dan mau mengerti kondisi menantu AE.

\section{Hasil}

Strategic family therapy yang diberikan kepada keluarga subjek selama empat sesi membuat hubungan komunikasi antara anggota keluarga satu sama lainnya menjadi lebih baik, diantaranya yaitu menjadi terbuka dengan keluh kesah masingmasing anggota keluarga yang dipendam, selain itu masingmasing anggota keluarga mampu membentuk perilaku baru yang telah disepakatiwalaupun dari beberapa tugas rumah belum dilakukan. Ibu SH masih canggung untuk memulai komunikasi dengan menantu AE, menantu AE 3 hari tidak komunikasi dengan ibu SH akan tetapi mejelaskan alasannya sehingga tidak terjadi salah paham.

Adapun grafik hasil penilaian selama intervensi sebagai berikut:

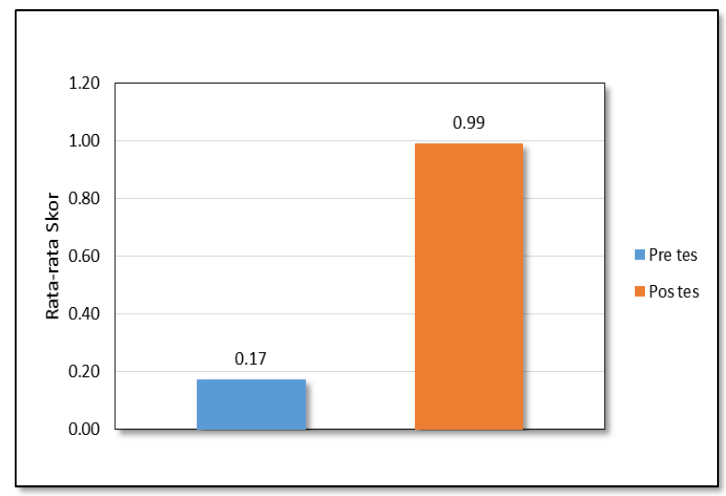




\section{Wahyu Utami | Strategic Family Therapy}

\section{Pembahasan}

Dalam menangani permasalahan dalam keluarga subjek, terapis menggunakan Strategic family therapy, memberikan keluarga dengan cara mengurangi factor risiko individu dan keluarga melalui intervensiterfokus yang meningkatkan hubungan keluarga bermasalah dan strategi keterampilan untuk membangun dan memperkuat hubungan keluarga. Salah satu target intervensi adalah hubungan keluarga yangbermasalah.

Strategic family therapy yang diberikan bertujuan untuk memperbaiki komunikasi antar anggota keluarga sehingga keluhan dan harapan dapat terpenuhi tanpa mengorbankan harapan-harapan anggota keluarga yang lain. Strategic family therapy dilakukan dengan strategi yang sudah dirancang dan dilaksanakan sesuai prosedur. Selain itu pendekatan terapi keluarga secara langsung menangani masalah-masalah yang ada dikeluarga yaitu fokus pada komunikasi keluarga yang digunakan saat ini dan treatment goals berasal dari permasalahan atau gejala yang ditampakkan (Winek, 2012).

Hasil intervensi diketahui bahwa masing-masing anggota memiliki harapan pada masing-masing anggota keluarga. Menantu bersedia menyempatkan diri beserta putra $\mathrm{AE}$ untuk menjenguk dan menyapa ibu SH, AE juga bersedia untuk kolaborasi dalam hal membeli kebutuhan dapur. Dilanjutkan dengan kedua ipar AE yang bersedia dengan bergantian menjenguk ibu SH dan bisa memahami kondisi ekonomi dan kesibukan menantu AE.Begitu juga dengan keinginan bapak PH kepada masing-masing anggota untuk tetap menjaga keharmonisan dan hubungan masing-masing anggota menjadi lebih baik setelah intervensi selesai.Hal tersebut juga terlihat pada saat terapis mendapatkan undangan datang ke rumah subjek, suasan rumah berbeda dari sebelum diberikannya intervensi, menantu AE yang sebelumnya cenderung diam sekarang mau untuk bercanda dengan masing-masing anggota keluarga.

Strategic family therapy yang diberikan kepada subjek dibuat bersama-sama oleh anggota keluarga. Tujuan Strategic 


\section{Wahyu Utami | Strategic Family Therapy}

family therapy ini berfokus pada konsep behavior, artinya tujuan keluarga tersebut merupakan perilaku yang nampak atau dapat di observasi. Selain itu, perilaku yang diinginkan juga harus mengikuti konsep behavioral dalam arti perilaku ang diinginkan pada akhir proses terapi, merupakan perilaku yang dapat berubah dalam konteks yang masuk akal atau perilaku yang masih dapat diperhitungkan.Tugas yang dirancang untuk anggota keluarga menggunakan teknik directive oleh Haley berupa daetar checklist yang bertujuan untuk membuat anggota keluarga melakukan sesuatu yang berbeda dan merasakan pengalaman yang berbeda, melibatkan terapis dengan proses treatment "meningkatkan hubungan dengan terapis", mengumpulkan beberapa informasi mengenai bagaimana respon setiap anggota keluarga pada tugas yang diberikan dan anggota keluarga dapat diarahkan pada suatu hal yang belum pernah dilakukan sebelumnya (Kerr \& Cristine, 2008).

\section{Kesimpulan}

Berdasarkan hasil assesmen, diketahui bahwa permasalahan dalam keluarga subjek karena masing-masing anggota memilih untuk diam daripada mendiskusikan masalah yang ada, sehingga komunikasi antar anggota keluarga tidak terjalin dengan baik. Intervensi yang diberikan adalah Strategic family therapy dengan tujuan untukmenghasilkan komunikasi yang efektif di dalam keluarga, ketika dalam keluarga memiliki masalah agar segera mengkomunikasi dengan baik-baik bagaimana solusinya dan tidak memilih untuk memendam masalah tersebut. Sehingga masing-masing anggota keluarga mampu membentuk perilaku baru yang telah disepakati walaupun masih ada anggota keluarga yang canggung untuk memulai komunikasi, akan tetapi hal tersebut tidak lagi menjadi masalah karena anggota mencoba untuk memberikan penjelasan alasannya seperti apa. Saran yang diberikan kepada masingmasing anggota keluarga adalah anggota keluarga dapat 


\section{Wahyu Utami | Strategic Family Therapy}

mengaplikasikan tugas-tugas rumah dan saling memahami kondisi satu sama lain.

\section{Daftar Pustaka}

Almasitoh, U.H. (2012). Model terapi dalam keluarga. Magistra No. 80 Th. XXIV Juni 2012 ISSN 0215-9511

Carr, A (2009). The effectiveness of family therapy and systemic interventions for child-focused problem. Journal of family therapy, 31, 3-45

Goldenberg, I., (2008). Family therapy (an overvierw, seventh edition). USAlThomson Brooks/Cole

Kerr \& Cristine. (2008). Family Art Therapy: Foundation of theory and practice. New York: Routledge (Taylor\&Francis Group).

Olson \& Blair, R,. (2007). Strategic family therapy for dysfunction parent. Academic Forum.

Pierey, F., \& Fish., S.,I., (1987). The theory and practice of structural and strategic family therapies: A delphie study. Journal of marintal and family therapy. 13 (2), 113-125.

Winek, L., (2012). Systemic family therapy from theory to practice, SAGE Publication, Inc. Student and instructor site.http//:www.mftlicenes.com/pdf/sg-chpt4.pdf.

Szapocznik J, Seth J. Schwartz, Joan A. Muir, \& C. Hendricks B. (2012). Brief Strategic Family Therapy: An Intervention to Reduce Adolescent Risk Behavior.Couple and Family Psychology: Research and Practice, American Psychological Association 1, (2), 134-145

Santrock, J. W. (2002). Adolescence (8 ed). New York: McGraw-Hill Co. 